\title{
Why Was the August Rainfall Pattern in the East Asia-Pacific Ocean Region in 2016 Different from That in 1998 under a Similar Preceding EI Niño Background?
}

\author{
DONG CHEN \\ Nansen-Zhu International Research Centre, Institute of Atmospheric Physics, Chinese Academy of Sciences, Beijing, China \\ YA GAO \\ Nansen-Zhu International Research Centre, Institute of Atmospheric Physics, Chinese Academy of Sciences, Beijing, \\ and Key Laboratory of Meteorological Disaster/Collaborative Innovation Center on Forecast and Evaluation \\ of Meteorological Disasters, Nanjing University of Information Science and Technology, Nanjing, China \\ HUIJUN WANG \\ Key Laboratory of Meteorological Disaster/Collaborative Innovation Center on Forecast and Evaluation of \\ Meteorological Disasters, Nanjing University of Information Science and Technology, Nanjing, China
}

(Manuscript received 8 September 2018, in final form 27 May 2019)

\begin{abstract}
Previous studies have noted that a strong El Niño event occurring in the preceding winter will result in westward stretching of the western North Pacific subtropical high (WPSH) in the following summer, causing anomalously high precipitation in the Yangtze-Huaihe River basin and anomalously low precipitation in southern China. The winters preceding the summers of 1998 and 2016 featured strong El Niño events, which, along with the El Niño event of 1982, represented the strongest El Niño events since 1950. Under these similar El Niño event backgrounds, the July precipitation anomaly in 2016 was similar to that in 1998, but the August precipitation anomalies in the two years featured opposite distributions. According to the atmospheric circulation analysis, we found that an anomalous ascending motion appeared over the Indian Ocean, while an anomalous descending motion appeared over the Pacific Ocean in August 1998. In addition, the WPSH stretched westward over southern China. However, the atmospheric circulation distribution in August 2016 was the opposite of that in 1998, and the WPSH was divided into eastern and western parts by the anomalous western Pacific cyclone. Further analysis showed that the number of tropical cyclones and typhoons over the western Pacific Ocean increased significantly in August 2016, and their activities were concentrated in the South China Sea (SCS)-southern China region and the western Pacific Ocean, resulting in the division of the WPSH. Therefore, the numbers, tracks, and strengths of tropical cyclones and typhoons were responsible for the differences in the anomalous precipitation distributions over the East Asia-Pacific Ocean region between August 2016 and August 1998.
\end{abstract}

\section{Introduction}

East Asia is one of the most densely populated regions in the world. Changes in the intensity and location of rainfall centers can threaten people's lives and cause significant economic losses. Therefore, the accurate prediction of rainfall plays a crucial role in the economic development and social stability of this region. The prediction of precipitation intensity and location, especially heavy precipitation, has always been a difficult challenge throughout the world (Wang et al. 2005).

\footnotetext{
Corresponding author: Ya Gao, gaoy@mail.iap.ac.cn
}

Because of the complex terrain and the interaction of multiclimate systems in East Asia, it is even more difficult to predict precipitation (Ma et al. 2015; Wang et al. 2012a,b).

El Niño-Southern Oscillation (ENSO), as one of the most significant interannual variabilities, has strongly impacted the East Asia-Pacific climate systems (Gao and Wang 2012; Gao et al. 2015a,b; Zhang et al. 2017). A large number of studies have analyzed the relationship between ENSO and the East Asian climate system, finding that ENSO had an important impact on the East Asian monsoon, the western North Pacific subtropical high (WPSH), the South Asian high (SAH), and the 
westerly jet stream. (Ju and Slingo 1995; Lin and Lu 2009; Xie et al. 2015; Xue et al. 2015). On this basis, the importance of ENSO in relation to summer precipitation in eastern China, especially in the Yangtze River basin, has been further studied (Huang et al. 1998; Lau and Weng 2001; Xue and Liu 2008; Zhang et al. 2016; Fan and Fan 2017). Taking the ENSO event in $1997 / 98$ as an example, the ENSO event provided a crucial climatic background for floods in the Yangtze River valley during the summer of 1998 (Tao et al. 1998; Zhang et al. 2016). Further studies have used ENSO signals to predict precipitation in the East Asia-Pacific Ocean region (Yang and Jiang 2014; Gao et al. 2015b; Zhang et al. 2016) and have achieved preliminary results.

The WPSH is one of the key components in the East Asian summer monsoon (EASM) system, the zonal extension or contraction of which over the western $\mathrm{Pa}$ cific is closely associated with the East Asian summer precipitation ( $\mathrm{Lu}$ and Dong 2001; Gao et al. 2011; Zhu et al. 2011; Du et al. 2017). A number of studies have suggested that ENSO is one of the major factors impacting the summer WPSH variation (T. Li et al. 2017; Wu et al. 2017a,b). It can intensify the WPSH through a wind-evaporation-sea surface temperature (SST) feedback mechanism (Wang et al. 2000; Paek et al. 2019) or through the Indian Ocean (Xie et al. 2009) or Maritime Continent SST (Sui et al. 2007; Zhou 2011). From the El Niño mature winter to the following decaying summer, the western North Pacific anticyclone can be sustained via a positive air-sea feedback, Indian Ocean capacitor, Rossby wave modulation, and so on. (Wang et al. 2000; Xie et al. 2009; T. Li et al. 2017; Wu et al. 2017a,b); thus, the ENSO can impact the East Asian summer precipitation through the strengthened WPSH (Wang and Li 2004; Liu et al. 2008; Zhang et al. 2017). The westward extension of the WPSH can enhance moisture transport from the western Pacific Ocean to the Yangtze River valley, resulting in an increase in summer precipitation in the middle to lower reaches of the Yangtze River valley and a decrease in precipitation in northern and southern China (Chang et al. 2000; Wang et al. 2009; Fan et al. 2013).

During the super-El Niño decaying summer in 1998, serious flooding appeared in the Yangtze River valley. In 2015, another comparable super-El Niño event occurred; however, under a similar super El Niño background, the summer rainfall over the Yangtze River valley in 2016 was weaker than that in 1998. Further research showed that in the following early summer of both 1998 and 2016, serious flooding occurred in the Yangtze River valley, whereas an anomalous negative rainfall pattern developed over southern China (Gao
2017; Gao et al. 2018). However, in August 2016, the precipitation distribution changed and was opposite to what occurred in July. This change is why there was less precipitation in the summer of 2016 than in 1998. Previous research has shown that the midlatitude circulation played an important role in the weak rainfall in the Yangtze River valley in August 2016 (C. Li et al. 2017; $\mathrm{He}$ et al. 2018). As the WPSH is one of the most important systems directly influencing summer precipitation over East Asia, how did the WPSH change? What differences in the WPSH were there between August 1998 and August 2016? Did the WPSH affect the summer rainfall over East Asia in August 2016? To answer these questions, in this study we investigate the factors that made the August precipitation in 2016 different from that in 1998 under an otherwise similar El Niño background. Following this introduction, section 2 describes the datasets and methods. Section 3 analyzes the precipitation distribution and the mechanisms for the differences between August 1998 and August 2016. Finally, a discussion and conclusions are provided in section 4 .

\section{Data and methods}

All datasets used in this study were taken from the Climate Prediction Center (CPC) Merged Analysis Precipitation (CMAP) satellite-gauge monthly product with a horizontal resolution of $2.5^{\circ} \times 2.5^{\circ}$ (Xie and Arkin 1997), the National Centers for Environmental Prediction (NCEP)-National Center for Atmospheric Research (NCAR) monthly reanalysis data with a horizontal resolution of $2.5^{\circ} \times 2.5^{\circ}$ (Kalnay et al. 1996), and the National Oceanic and Atmospheric Administration (NOAA) monthly Extended Reconstructed Sea Surface Temperature dataset (ERSST, version 3b) with a horizontal resolution of $2^{\circ} \times 2^{\circ}$ (Smith et al. 2008). In this study, the selected time period is from 1979 to 2016 . The annual typhoon number in the western North Pacific Ocean was taken from the International Best Track Archive for Climate Stewardship (IBTrACS v03r10; Knapp et al. 2010). The IBTrACS is the most complete collection of the best track datasets currently available and includes data from the World Meteorological Organization (WMO) Regional Specialized Meteorological Centres (RMSCs) and Tropical Cyclone Warning Centers (TCWCs), the Joint Typhoon Warning Center (JTWC), the Shanghai Typhoon Institute, the Hong Kong Observatory, and several historical archives (Kruk et al. 2010). Here, we use the Saffir-Simpson scale to identify a typhoon, which is defined as wind speeds equal to or greater than $74 \mathrm{mph}$ or $33.1 \mathrm{~m} \mathrm{~s}^{-1}$ (http://www.usno.navy.mil/JTWC/frequentlyasked-questions-1/frequently-asked-questions). 
(a) Precip. ano
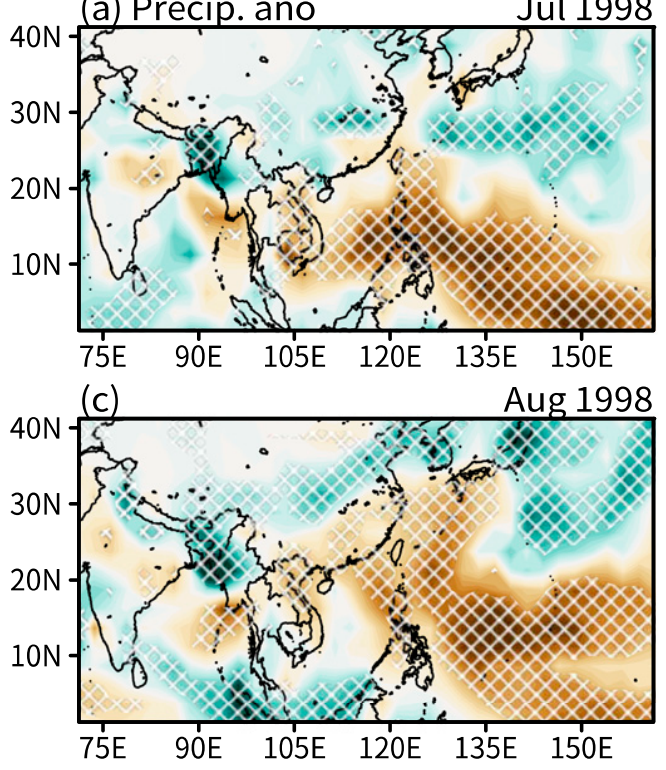

(b)
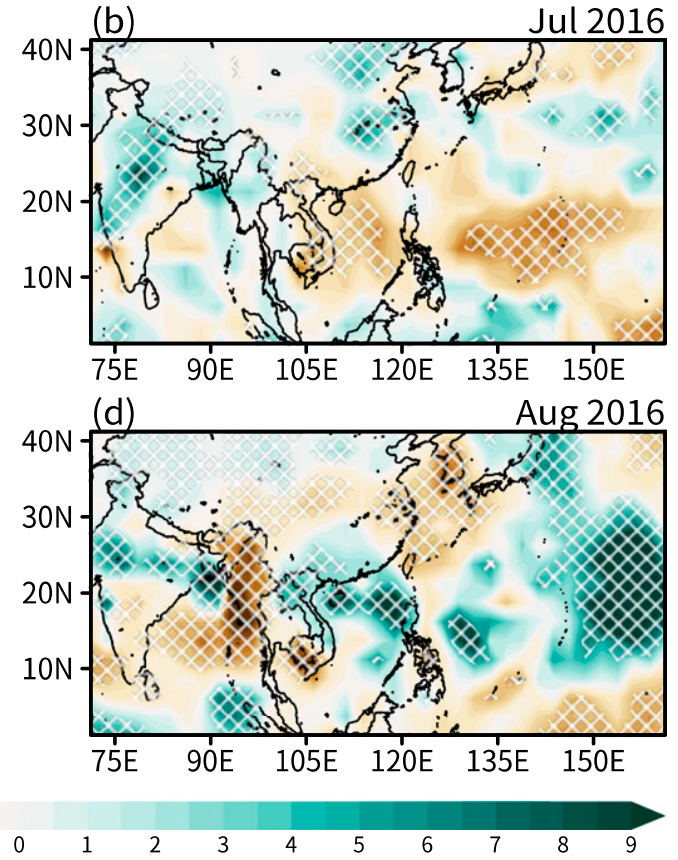

FIG. 1. Anomalous precipitation distributions $\left(\mathrm{mm} \mathrm{day}^{-1}\right.$ ) over the East Asia-Pacific Ocean region in (a) July and (c) August 1998 and (b) July and (d) August 2016. The grid area indicates anomalous conditions exceeding one standard deviation.

In this paper, the anomaly is defined as an anomaly relative to the years of 1979-2016. For there to be a significant anomaly of a typical year, a significant test is defined as a region with more than one standard deviation (Otterå 2008).

Based on Emanuel and Nolan's (2004) work, a modified genesis potential index (GPI) (Emanuel 2010) was used to determine the influences of the large-scale environment on tropical cyclone (TC) genesis, which is defined as follows:

$$
\mathrm{GPI}=\frac{a\left[\min \left(|\eta|, 4 \times 10^{-5}\right)\right]^{3}\left[\mathrm{max}\left(\mathrm{PI}-35 \mathrm{~m} \mathrm{~s}^{-1}, 0\right)\right]^{2}}{\chi^{4 / 3}\left(25 \mathrm{~m} \mathrm{~s}^{-1}+\mathrm{VS}\right)^{4}},
$$

where $a$ is a normalizing coefficient, $\eta$ is the absolute vorticity at $850 \mathrm{hPa}\left(\mathrm{s}^{-1}\right), \chi$ is the moist entropy deficit, PI is the potential intensity $\left(\mathrm{m} \mathrm{s}^{-1}\right)$, and VS is the vertical wind shear between 200 and $850 \mathrm{hPa}\left(\mathrm{m} \mathrm{s}^{-1}\right)$.

\section{Results}

The El Niño events in the winters of $1997 / 98$ and 2015/16 as two strongest events since observational records, their intensities were higher than twice the standard deviation of the Niño-3.4 index, which attracted wide attention from the academic community (C. Li et al. 2017; Gao et al. 2018; Huangfu et al. 2018). Using NOAA and Hadley sea surface temperature data, we analyzed the Niño-3.4 $\left(5^{\circ} \mathrm{S}-5^{\circ} \mathrm{N}, 170^{\circ}-120^{\circ} \mathrm{W}\right)$ and Niño-3 $\left(5^{\circ} \mathrm{S}-5^{\circ} \mathrm{N}, 150^{\circ}-90^{\circ} \mathrm{W}\right)$ indices and found that the two El Niño events had similar intensities and decaying processes (figure not shown), which was consistent with the results of previous studies (C. Li et al. 2017; Huangfu et al. 2018). Gao et al. (2018) analyzed the early summer (MayJuly) precipitation anomaly pattern in the pan-Asian monsoon region and its physical mechanism during a strong El Niño decaying year. The early summer precipitation anomaly distribution in 2016 was consistent with that in 1998; however, the August precipitation pattern was different between these two years. As Fig. 1 shows, in 1998, the anomalous July precipitation increased over the Yangtze-Huaihe River basin-East China Sea (ECS)Japan Sea region and decreased over the southern ChinaPhilippine Sea region. The August precipitation anomaly pattern was consistent with the July pattern, but the rainbelt moved northward, producing more rainfall over the upper reaches of the Yangtze River, the Bohai Sea, the Korean Peninsula, and the Sea of Japan and less rainfall over southern China, the ECS, and the Philippine Sea. The July precipitation anomaly in 2016 resembled that in 1998, with more rainfall over the Yangtze-Huaihe River basin and less rainfall over southern China. However, the precipitation anomaly pattern was the reverse in August 2016, which featured anomalously low rainfall over the Yangtze-Huaihe River basin and anomalously high 

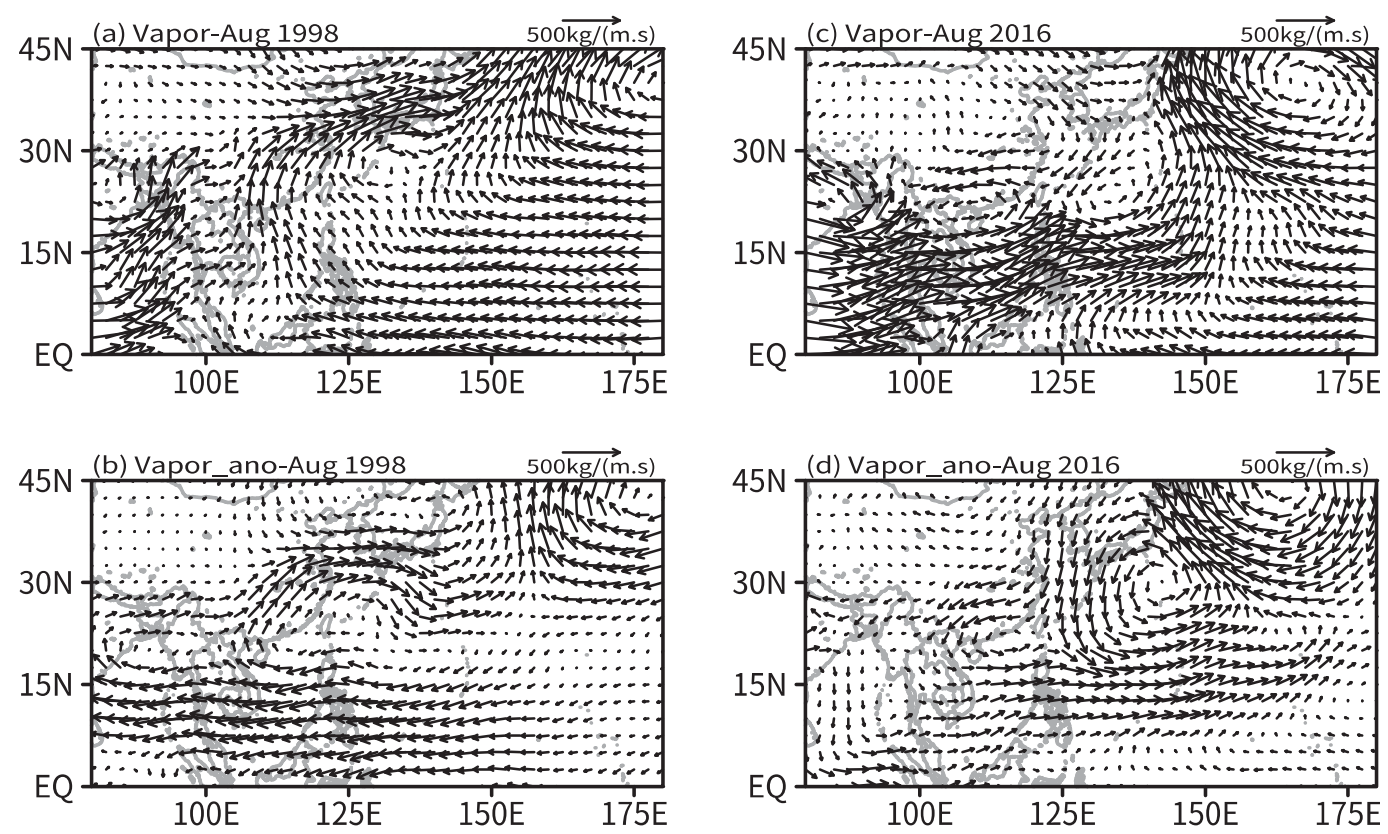

FIG. 2. Vertically (from the surface to $300 \mathrm{hPa}$ ) integrated water vapor transport field $\left(\mathrm{kg} \mathrm{m}^{-1} \mathrm{~s}^{-1}\right.$ ) during August (a) 1998 and (c) 2016. Anomalous vertically (from the surface to $300 \mathrm{hPa}$ ) integrated water vapor transport field $\left(\mathrm{kg} \mathrm{m}^{-1} \mathrm{~s}^{-1}\right)$ during August (b) 1998 and (d) 2016.

rainfall over southern China, the South China Sea (SCS), and the tropical western Pacific Ocean.

Figure 2 plots the vertically integrated water vapor transport and its anomalies during August 1998 and 2016. In August 1998, the water vapor was transported along the western edge of the WPSH to arrive at the
Yangtze River valley (Fig. 2a). However, in 2016, the path of the moisture transport was more southward, so that the water vapor was transported eastward along the tropical ocean and converged with the moisture from the western Pacific, then continued to be transported northward (Fig. 2c). As the anomalies field (Fig. 2b)
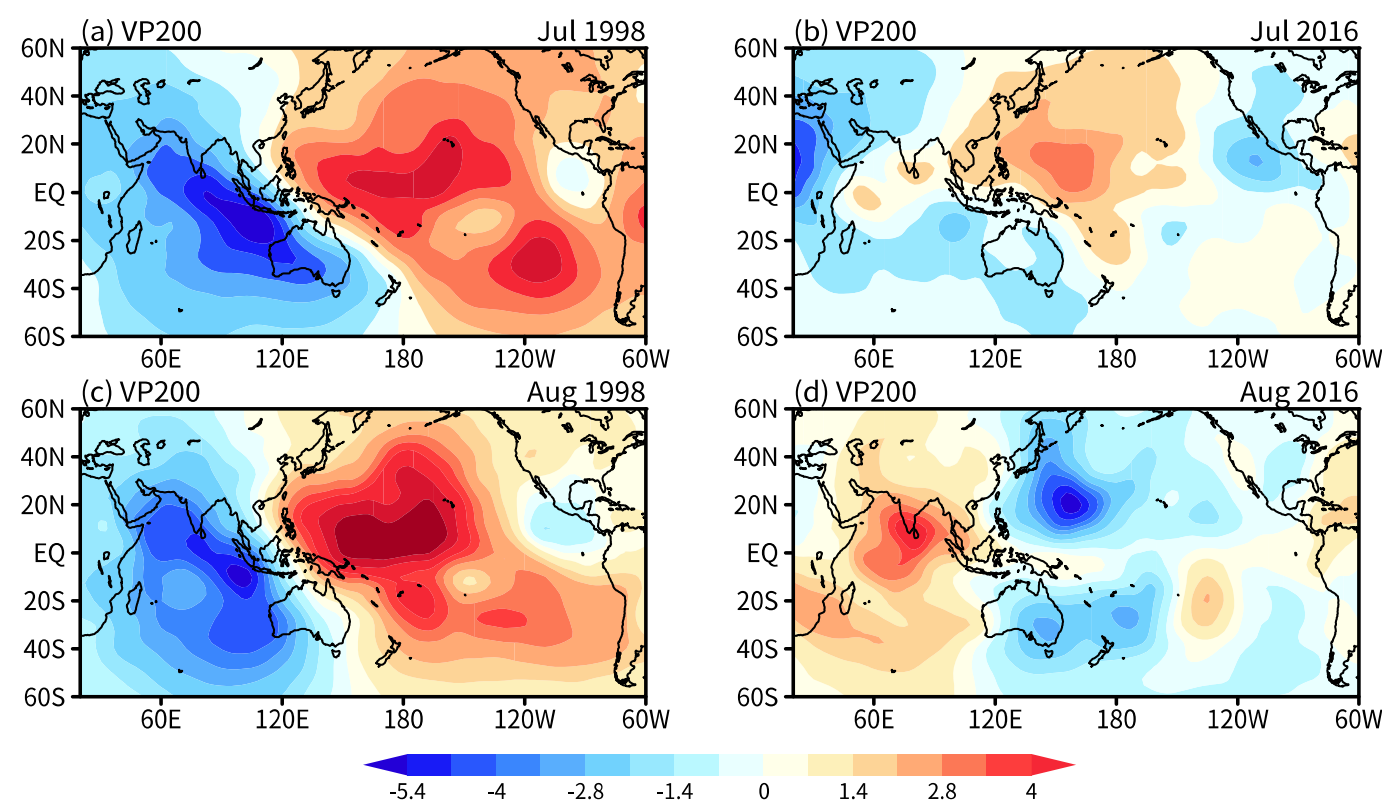

FIG. 3. Anomalous velocity potential $\left(10^{6} \mathrm{~m}^{2} \mathrm{~s}^{-1}\right)$ at 200-hPa geopotential height in (a) July and (c) August 1998 and (b) July and (d) August 2016. 

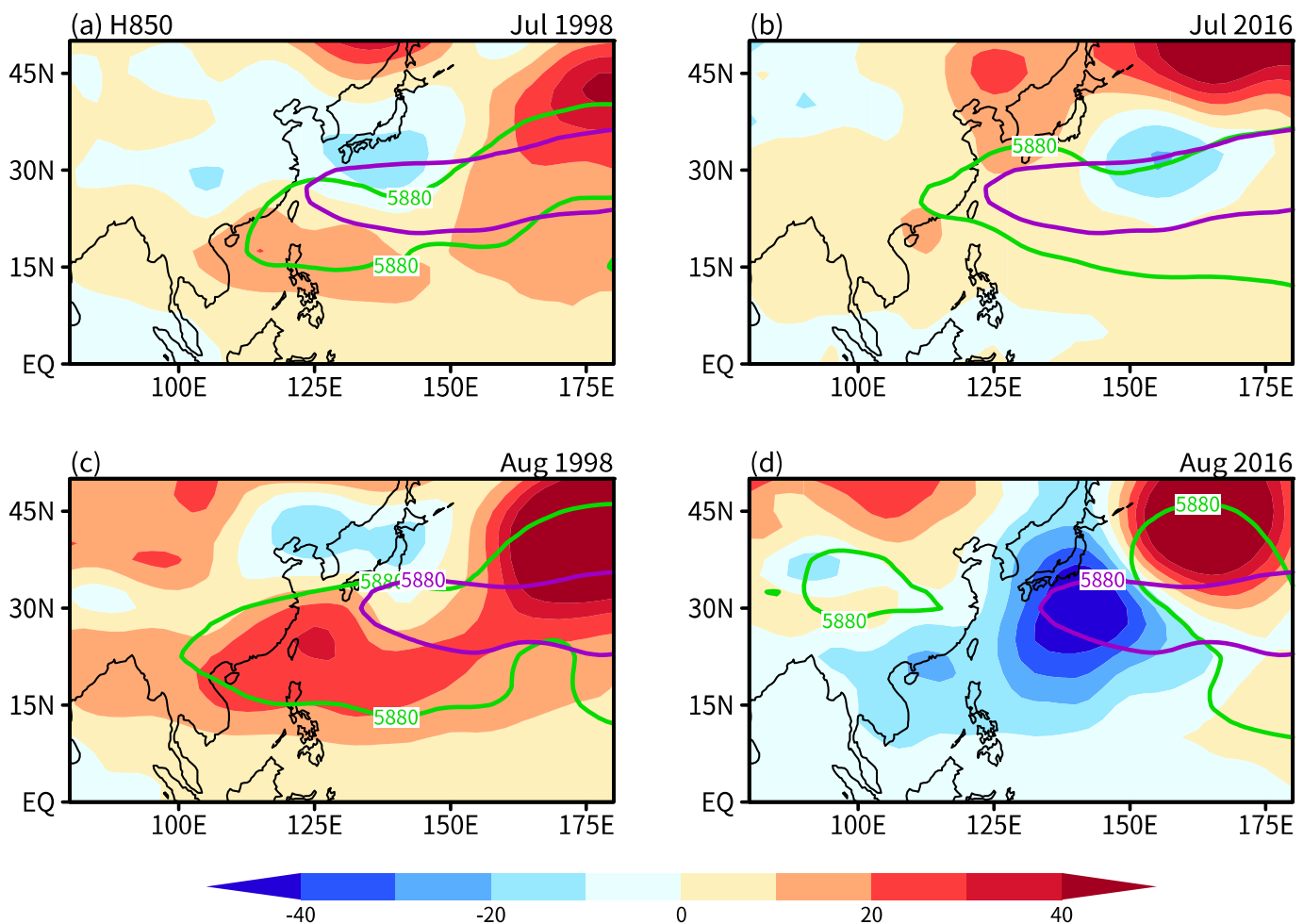

FIG. 4. Anomalous 850-hPa geopotential height field (gpm) in (a) July and (c) August 1998 and (b) July and (d) August 2016. Purple lines represent the climatology of $5880 \mathrm{gpm}$ at 500-hPa geopotential height during 19792016. Green lines represent the 5880-gpm line at 500-hPa geopotential height in (a) July and (c) August 1998 and (b) July and (d) August 2016.

shows, the water vapor transport field over the Bay of Bengal (BOB), Indochina Peninsula, and southern China was controlled by an anomalous anticyclone in August 1998, resulting in less rainfall in these regions. The moisture from the tropical western Pacific Ocean was transported westward through the Philippine peninsula, the Indochina Peninsula, and the BOB and was eventually transported to the upper reaches of the Yangtze River, the Bohai Sea, the Korean Peninsula, and the Sea of Japan to the northeast, resulting in more rainfall in these regions. The water vapor transport pattern in August 2016 was opposite of that in August 1998 and involved an anomalous cyclone over Indochina, southern China, and the tropical western Pacific Ocean (Fig. 2d). Thus, the moisture from the tropical western Pacific Ocean was transported along the eastern coast of China to southern China, leading to more rainfall in southern China, the SCS, and the tropical western Pacific Ocean. However, because the moisture did not reach the Yangtze-Huaihe River basin, less rainfall occurred in that region.

Furthermore, we analyzed the velocity potential field (Fig. 3) and found that an anomalous convergence appeared at lower levels (figure not shown) and that an anomalous divergence appeared at upper levels over the tropical Indian Ocean in July 1998, leading to an ascending motion. However, an anomalous descending motion occurred over the tropical central-western $\mathrm{Pa}$ cific Ocean due to an upper-level convergence and lower-level divergence (figure not shown). The velocity potential field in August was consistent with that in July 1998 (Fig. 3c). This distribution led to the anomalous cyclonic circulation over the tropical central-western Pacific Ocean and anomalous easterlies over the tropical western Pacific Ocean and Indian Ocean (Fig. 2b). The vertical motion pattern in July 2016 resembled that of July 1998. However, the August pattern in 2016 was opposite that in both August 1998 and July 2016, which involved an anomalous convergence (divergence) over the tropical western Pacific Ocean in the lower levels (upper levels) and an anomalous divergence (convergence) over the Indian Ocean in the lower levels (upper levels), inducing anomalous westerlies over the tropical western Pacific Ocean and Indian Ocean (Fig. 2d).

To investigate why the vertical motions were different during these two typical El Niño decaying years, we plotted the 850-hPa geopotential height field (Fig. 4). As Fig. 4a shows, compared to the climatology $\left(125^{\circ} \mathrm{E}\right)$, the 

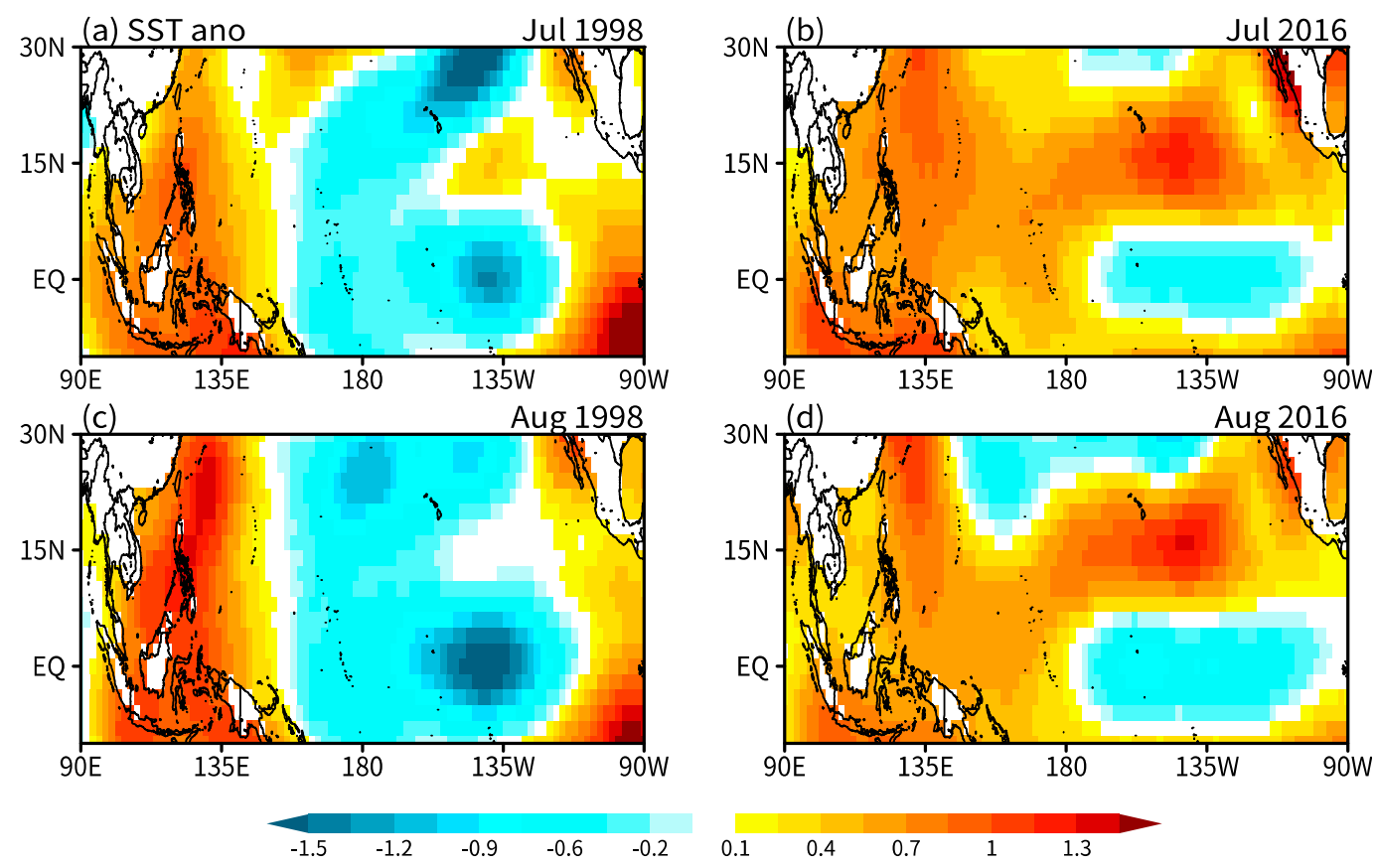

FIG. 5. Anomalous SST fields (K) during (a) July and (c) August 1998 and (b) July and (d) August 2016.

western ridge at $5880 \mathrm{gpm}$ at the $500-\mathrm{hPa}$ geopotential height was located at approximately $112^{\circ} \mathrm{E}$ in July 1998 , indicating westward stretching of the WPSH. In addition, an anomalous anticyclone was also present over the tropical western Pacific Ocean at the $850-\mathrm{hPa}$ geopotential height field (Fig. 4a). In August, the location of climatology of the 5880-gpm line was farther east than that in July (purple lines from July to August). However, the 5880gpm line was more westward in August 1998 (green lines from July to August) (Fig. 4c), indicating that the WPSH extended farther westward over southern China, inducing less rainfall there. Compared to the climatology, the WPSH extended westward in July 2016, as well, but the location was farther to the north than that in July 1998 (Fig. 4b). In August 2016, from the west ridge point of the 5880-gpm line, the WPSH extended more westward than in 1998. However, the WPSH was divided into two parts by the anomalous western Pacific cyclone. One center of the WPSH was located over the eastern area of northwestern China, and the other was located over the Pacific, spanning the region of $150^{\circ}-160^{\circ} \mathrm{E}$ (Fig. $4 \mathrm{~d}$ ). The anomalous cyclone occurring over the southern China, SCS, and western Pacific Ocean enhanced rainfall in these regions.

Previous studies noted that the preceding winters of 1998 and 2016 had strong El Niño events with similar intensities (C. Li et al. 2017). Both of these two events decayed rapidly and disappeared until June of the following year (C. Li et al. 2017; Gao et al. 2018). Many studies have indicated that a preceding ENSO event can lead to westward stretching of the WPSH in the following summer and can impact the precipitation distribution in East China (Wang et al. 2000; Liu et al. 2008; Xie et al. 2009; Fan et al. 2013; T. Li et al. 2017; Wu et al. 2017a,b; Gao et al. 2018). In addition, previous studies have shown that anomalous high temperature in the western Pacific Ocean is also conducive to the extension of the WPSH $(\mathrm{Hu} 1997$; Zhou et al. 2009; Chen et al. 2015), and such SST anomalies were similar in the summers of 1998 and 2016. However, why did the precipitation anomaly pattern in August 2016 differ from that in 1998, and why did drastic changes occur from positive to negative precipitation anomalies in the Yangtze River valley? Why was the WPSH cut by the anomalous cyclone in August 2016? To answer these questions, we plotted the SST anomaly field in July and August during 1998 and 2016 (Fig. 5). In 1998, the SST anomaly distributions in July and August were generally consistent. The anomalous warm SST values were located over the Maritime Continent and favored the extension of the WPSH, and the anomalously cold SST values were located over the central Pacific Ocean. The SST anomaly patterns in July and August 2016 were consistent with those in 1998, with an anomalous warm Maritime Continent and an anomalous cold equatorial central Pacific Ocean. Given the high persistence of the SST patterns in July and August, the SST could not have been responsible for abruptly dividing the WPSH via the western Pacific anomalous cyclone. Therefore, what other mechanism was responsible for this phenomenon? 

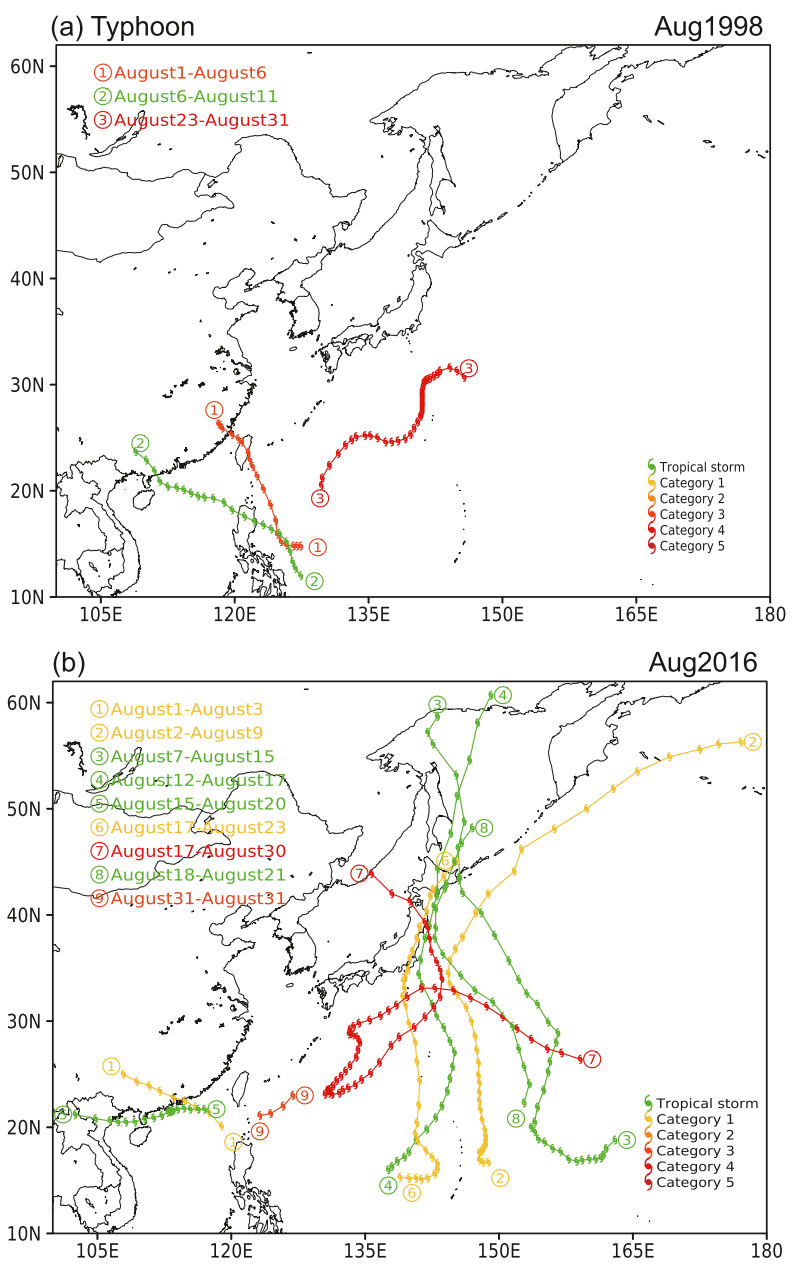

FIG. 6. Tropical cyclones and typhoon tracks (with 3-h intervals) and strengths (defined by the Saffir-Simpson scale) in August (a) 1998 and (b) 2016.

Figure 6 shows the TC and typhoon tracks and strengths in August 1998 and 2016. One TC and two typhoons occurred in August 1998, mainly over the Philippine Sea $\left(10^{\circ}-20^{\circ} \mathrm{N}\right)$. One typhoon generated in the beginning of the month and one generated at the end of the month, and the TC generated in early August. Two of these storms traveled along northwestern paths, reached southern China, and then disappeared; the other traveled along a northeastern path and arrived at the Sea of Japan (Fig. 6a). In 2016, four TCs and five typhoons occurred in August. Three storms with short paths, one TC and two typhoons, were generated over the Philippine peninsula; two traveled along a western path to southern China and the Indochina Peninsula and disappeared, and the other generated on the last day in August and developed along a northeastern path. Another six events, three TCs and three typhoons, generated over the tropical western Pacific Ocean and generally traveled along northern paths to arrive in subtropical regions. The TC activities in August 2016 occurred during the entire month without interruption, and the number of TCs in August 2016 was the largest in history. It is worth pointing out that at most four TCs can exist simultaneously in the western North Pacific, but this condition is rare in history. The region covered by the TC and typhoon tracks was consistent with the anomalous cyclonic circulation area over the Indochina Peninsula, southern China, the SCS, and the western Pacific Ocean in the 850hPa geopotential height field during August 2016 (Fig. 4d). We also used the daily data to analyze the changes in the WPSH in these two years (Fig. 7). During late July 2016, the TC cut the WPSH into two parts on 25 July. Subsequently, the subtropical high pattern recovered and continued to be cut off by the new northward-traveling cyclones and typhoons in August 2016. This occurred because the newly generated TCs were more likely to travel toward the north along the western edge of the eastern part of the WPSH. Thus, owing to the frequent occurrence of these typhoons during this period and the combination of multiple factors, such as the generating location and the northward path, the WPSH was always in a state of being separated from east and west. The results are consistent with the monthly data, indicating that the TC and typhoon tracks significantly and directly influenced the WPSH location and therefore modified the precipitation distribution in August 2016.

Therefore, the precipitation anomaly distribution in August 2016 was opposite that in August 1998 over East Asia and the Pacific Ocean and was mainly influenced by the divided WPSH. The WPSH was divided by the western Pacific cyclone, resulting in more rainfall in southern China and less rainfall in the Yangtze-Huaihe River basin. Furthermore, we investigated the corresponding typhoon frequencies and tracks and found that there were only three TCs and typhoons in August 1998 and that their activity ranges were near the Philippine Sea. However, in August 2016, there were nine TCs and typhoons, and activity occurred in the SCS, southern China, and the western Pacific Ocean. The intensive TC and typhoon activities caused a significant reduction in the monthly air pressure over southern China, the SCS, and the western Pacific Ocean, resulting in the WPSH dividing into two parts. One part was located over western China, and the other part was located over the tropical centralwestern Pacific Ocean.

\section{Discussion and conclusions}

\section{a. Conclusions}

Previous studies have shown that strong El Niño events occurred in the preceding winters of both 1998 and 2016. However, the precipitation anomaly distribution found in 

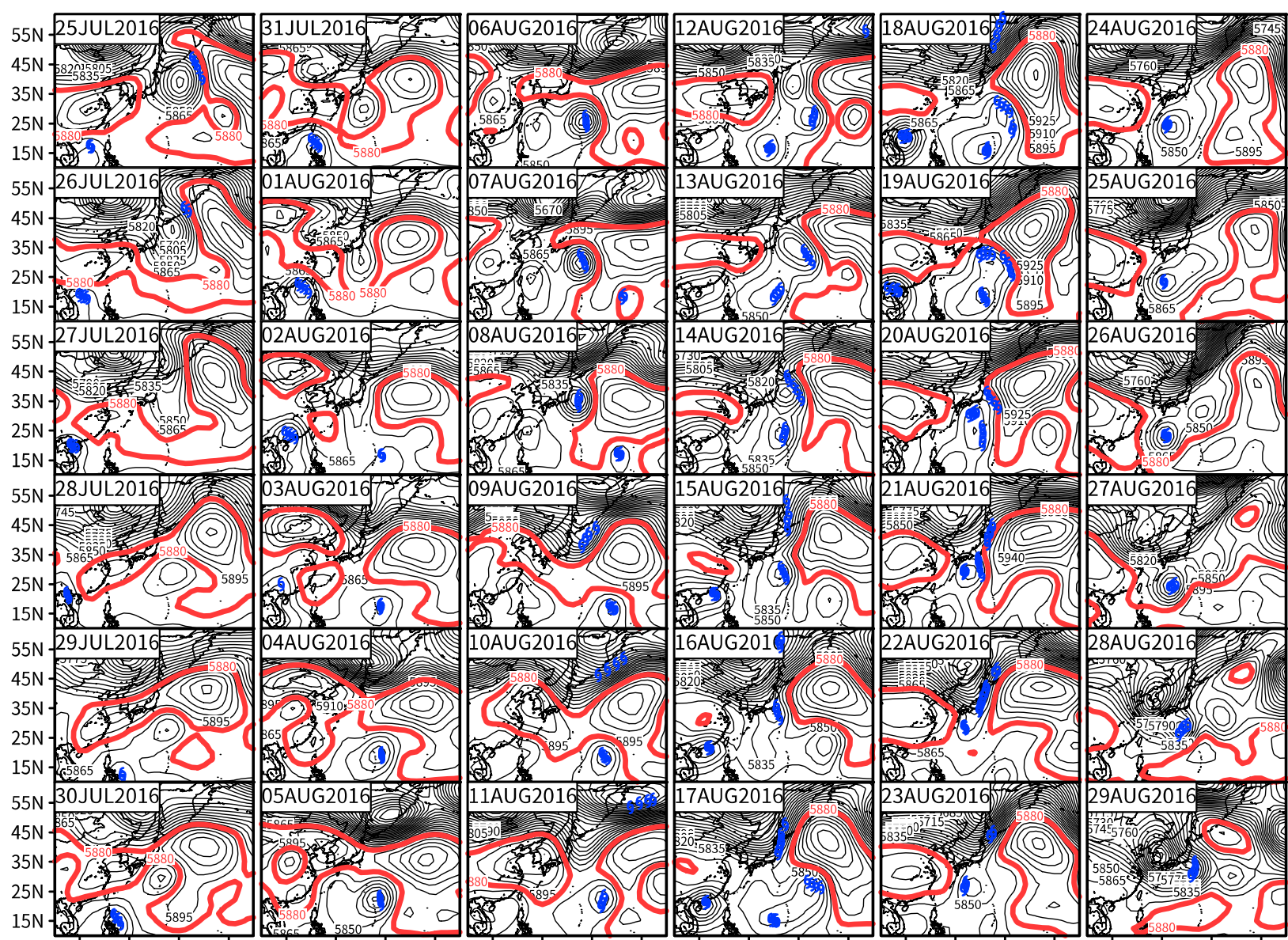

110E 130E 150E 170E 110E 130E 150E 170E 110E 130E 150E 170E 110E 130E 150E 170E 110E 130E 150E 170E 110E 130E 150E 170E

FIG. 7. Daily 500-hPa geopotential height field (gpm) during 25 Jul-29 Aug 2016. The typhoon symbols indicate the tracks (with 3-h intervals) of the named typhoons. The thick red contours are the 5880-gpm line at daily 500-hPa geopotential height.

the following August was reversed between these two years. In 1998, the precipitation anomalies had high persistence in July and August and mainly featured enhanced rainfall over the Yangtze-Huaihe River basin, the Korean Peninsula, and the Sea of Japan and reduced rainfall over the eastern Indochina Peninsula, southern China, the ECS, and the tropical western Pacific Ocean. The anomalous precipitation in July 2016 was consistent with that in 1998. However, in August 2016, an anomalously decreased amount of rainfall occurred in the Yangtze-Huaihe River basin and the Korean Peninsula and an anomalously increased amount of rainfall occurred over the eastern Indochina Peninsula, southern China, the ECS, and the tropical western Pacific Ocean, which is opposite to the pattern in 1998.

According to atmospheric circulation analysis, we found that in August 1998 an anomalous ascending motion appeared over the Indian Ocean, and an anomalous descending motion appeared over the Pacific Ocean. In addition, the WPSH extended westward to southern
China, inducing less rainfall over the southern Chinatropical western Pacific Ocean region and more rainfall over the Yangtze-Huaihe River basin-Korean Peninsula region. However, in August 2016, the precipitation anomaly pattern was opposite of that in 1998 and featured a descending motion over the Indian Ocean and an ascending motion over the western Pacific Ocean. In addition, the WPSH in 2016 was cut by the western Pacific cyclonic circulation, one part of which was located over western China and the other part of which was located over the central-western to northwestern Pacific Ocean, causing the anomalous rainfall pattern formed in August 2016.

To investigate the primary responsible mechanism, we analyzed the SST field. These data showed that the SST in both 1998 and 2016 had high persistence from July to August, mainly displaying anomalously high temperatures over the Maritime Continent and anomalously low temperatures over the equatorial central Pacific Ocean. Therefore, the SST change was not the 

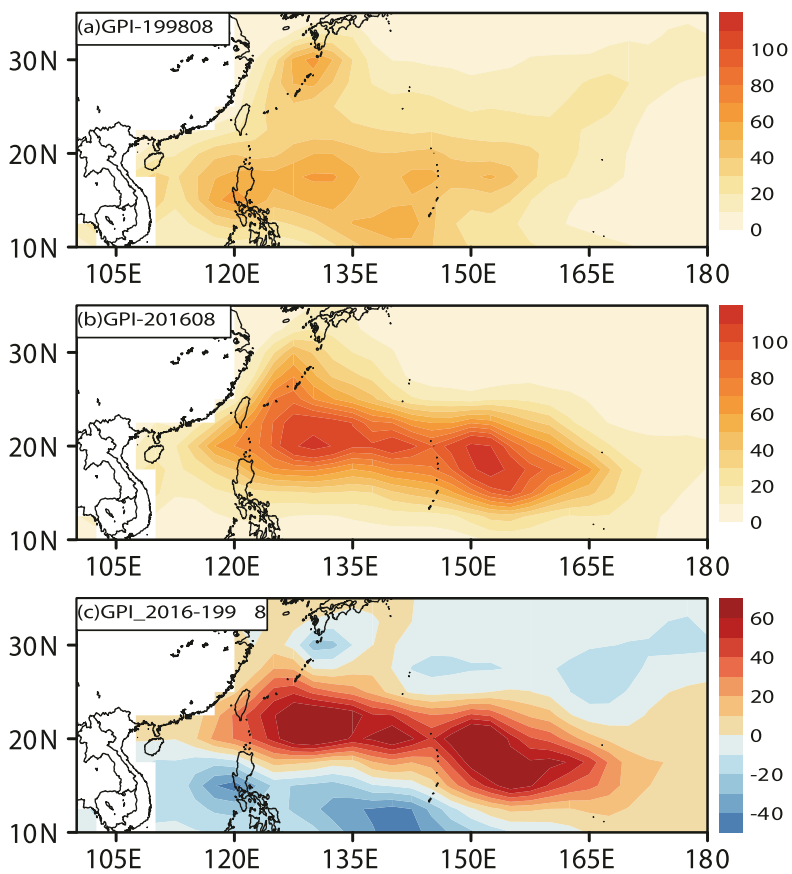

FIG. 8. Spatial distributions of GPI in (a) August 1998 and (b) August 2016, and (c) their difference [(b) minus (a)].

main factor responsible for the WPSH being abruptly divided by the western Pacific cyclone in August 2016. Further analysis revealed that compared to the activity in August 1998, the TC and typhoon activity in August 2016 was significantly increasing. The main range of activity extended from southern China and the SCS to the western Pacific Ocean, which was the dominant factor inducing the division of the WPSH into two parts. Therefore, the primary factor responsible for the different precipitation anomaly patterns observed in $\mathrm{Au}-$ gust 2016 and August 1998 over the East Asia-Pacific Ocean region was the significantly higher number of TCs and typhoons in August 2016. Because TC genesis is closely related to large-scale environments, we calculated the monthly GPI to represent the location of TC genesis to analyze the large-scale conditions for TC genesis (Yan et al. 2015; Yan et al. 2016; Yan and Zhang 2017). Figure 8 shows the spatial distributions of the GPI in August 1998 and August 2016, and their differences. In August 1998, the maximum center of the GPI was located east of the Philippine peninsula $\left(10^{\circ}-20^{\circ} \mathrm{N}, 110^{\circ}-\right.$ $150^{\circ} \mathrm{E}$ ). In August 2016, the maximum center of the GPI was located at nearly $20^{\circ} \mathrm{N}$, which was farther northeast than in 1998. In addition, the intensity of the GPI maximum center in 2016 was much larger than that in 1998 (Fig. 8c), revealing more TC genesis in August 2016. Thus, the intensity of the spatial distribution of the GPI in August 1998 and 2016 was fairly consistent with the
TC genesis location (Fig. 6), indicating that the GPI distribution can successfully capture the large-scale environmental changes in these two years.

To analyze the relative role of the large-scale environmental factors in TC genesis, we calculated the relative contribution of each GPI term to the GPI change. The GPI can be expressed as four terms: absolute vorticity at $850 \mathrm{hPa} \eta$, potential intensity (PI), moist entropy deficit $\chi$, and vertical wind shear between 200 and $850 \mathrm{hPa}$ (VS). The specific method was as follows. First, the first to fourth GPI terms of 1998 were replaced by those of 2016. Then, this result was subtracted from the 1998 GPI. Thus, the relative contribution of each GPI term was calculated (Fig. 9). As Figs. $9 \mathrm{~b}$ and $9 \mathrm{c}$ show, the maximum centers of the PI and $\chi$ were located over $135^{\circ}-165^{\circ} \mathrm{E}$, at approximately $20^{\circ} \mathrm{N}$, which is consistent with the location of the TC genesis in 2016 (Fig. 6) and the GPI maximum difference between 2016 and 1998 (Fig. 8c). Therefore, a higher number of typhoons and tropical storms moved northward in the eastern part of the western Pacific in August 2016 and in August 1998, which was mainly explained by the thermodynamic terms (PI and $\chi$ ). These two terms resulted in the division of the WPSH. In addition, three typhoons and tropical storms developed near the Philippine peninsula in both 1998 and 2016, and the effect of VS mainly shifted the TC genesis northward in 2016. This paper explored the impact of synoptic scale changes on longterm climate change from a new perspective, which provides new ideas for precipitation prediction in East Asia.

\section{b. Discussion}

As a warm pool, the western North Pacific (WNP) can provide abundant thermodynamic resources for TC formation during most of the year (Trenberth 2007). Thus, the WNP has the most TCs in the world. ENSO, as an important interannual climate variability, can affect TC activities (He et al. 1999; Wang and Chan 2002). During the El Niño developing phase, the number of TCs generally increases over the southeastern part of the WNP, and decreases over the northwestern part in summer, which is due to the El Niño-induced lower-level westerlies over the equator (Wang and Chan 2002). However, in the following El Niño decaying summer, although the local SST changes very little, the number of TCs formed decreases over the WNP because of the Philippine Sea anticyclone (Wang and Chan 2002; Du et al. 2011; Li and Zhou 2012). For the location, the TC genesis often occurs in the southeast during an El Niño event and in the northwest during a La Niña event (Wang and Chan 2002). In this paper, during the El Niño decaying 

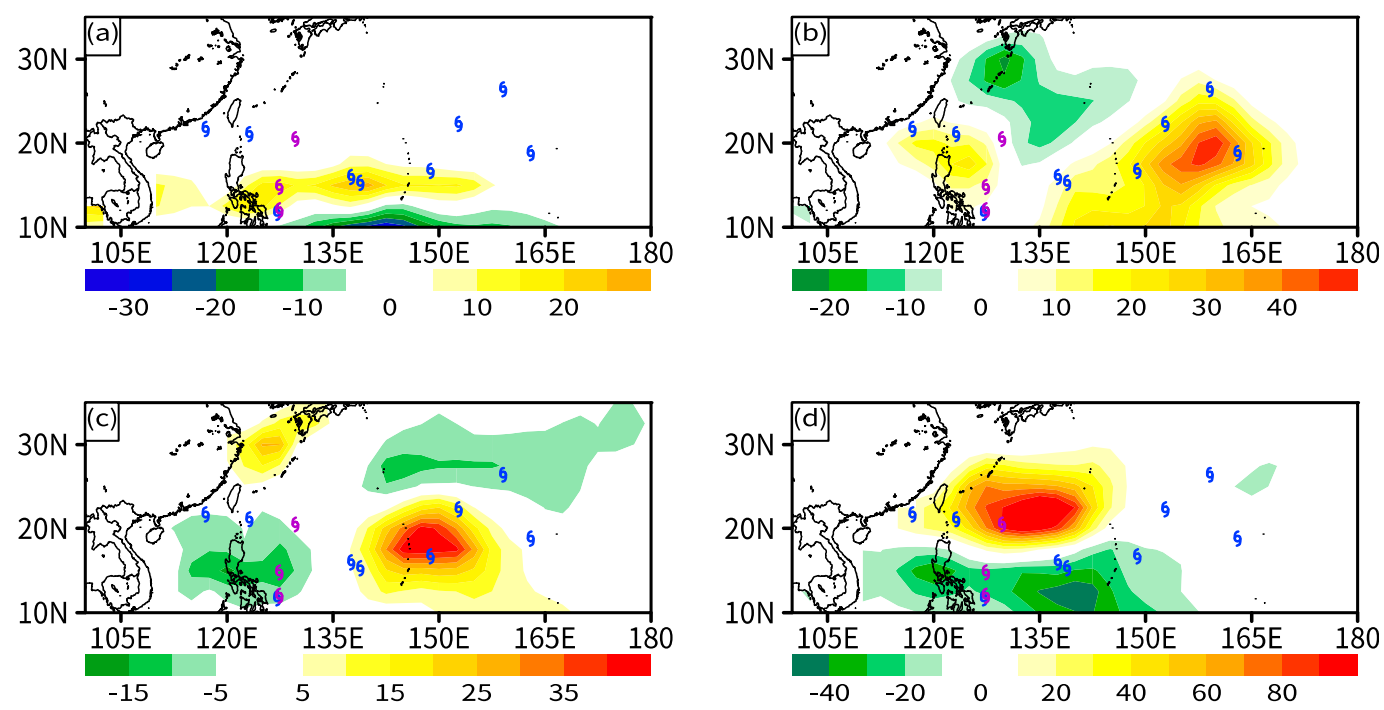

FIG. 9. Epochal difference of GPI between 1998 and 2016 induced by (a) absolute vorticity at $850 \mathrm{hPa} \eta$, (b) potential intensity (PI), (c) moist entropy deficit $\chi$, and (d) vertical wind shear between 200 and $850 \mathrm{hPa}$ (VS). When calculating the GPI induced by a determined parameter, the determined parameter being examined was replaced by the 2016 value, and the other of three parameters used were the 1998 values. The purple typhoon symbols indicate the genesis locations (with 3-h intervals) of the named typhoons in 1998. The blue typhoon symbols indicate the genesis locations (with 3-h intervals) of the named typhoons in 2016.

summer of August 2016, the number of TCs increased and they generated in the east, which is not consistent with the findings of previous research.

Huangfu et al. (2018) compared the differences of TC activities between 1998 and 2016 during two super-El Niño decaying summers. They found that the active typhoon in 2016 was attributed to the eastward extension of the monsoon trough (MT), more active tropical depression wave activities, and the slow developing process of La Niña-like SST during this year. The relatively slower La Niña developing phase sustained the warmer SST anomalies and anomalous cyclones and may have impacted the MT. However, the averaged SST was normally high enough for TC formation over the Asian monsoon region during most of the year (Trenberth 2007). Thus, except for the effect of the ENSO, TC was related to many factors. Previous studies showed that the large-scale atmospheric circulation conditions over this region play a more important role in affecting TC activities (Harr and Elsberry 1995; Trenberth 2007; Park et al. 2013; Lin and Chan 2015).

As mentioned above, first, the numbers and genesis locations of TCs in August 2016 were different than the results of the ENSO decaying-induced TC changes. Second, except for the ENSO impact, the number, location, and intensity of TCs were also related to many factors, such as the quasi-biennial oscillation (QBO), Madden-Julian oscillation (MJO), MT, and North Pacific Oscillation (NPO) (Chan 1995; Li and
Zhou 2013a, 2013b; Chen et al. 2015; Huangfu et al. 2018). However, this paper mainly focused on the reason that directly impacted the rainfall distribution differences between August 1998 and 2016. The direct impact of the August rainfall was attributed to the separated WPSH induced by the active TCs in 2016. Identifying the factors responsible for TC genesis and the predicting the number and intensity of typhoons require further research. In summary, to study shortterm climate predictions, in addition to considering the impact of climate change on a monthly scale, it is necessary to consider changes on the synoptic scale and intraseasonal scale.

Acknowledgments. This research was supported by the National Key Research and Development Program of China (Grant 2017YFC1502304), the National Natural Science Foundation of China (Grants 41421004, 41875110, 41705066, and 41505070), and the CAS-PKU Joint Research Program.

\section{REFERENCES}

Chan, J. C. L., 1995: Tropical cyclone activity in the western North Pacific in relation to the stratospheric quasi-biennial oscillation. Mon. Wea. Rev., 123, 2567-2571, https://doi.org/10.1175/ 1520-0493(1995)123<2567:TCAITW>2.0.CO;2.

Chang, C., Y. Zhang, and T. Li, 2000: Interannual and interdecadal variations of the East Asian summer monsoon and tropical 
Pacific SSTs. Part I: Roles of the subtropical ridge. J. Climate, 13, 4310-4325, https://doi.org/10.1175/1520-0442(2000)013<4310: IAIVOT $>2.0 . \mathrm{CO} ; 2$.

Chen, D., H. J. Wang, J. P. Liu, and G. P. Li, 2015: Why the spring North Pacific Oscillation is a predictor of typhoon activity over the western North Pacific. Int. J. Climatol., 35, 3353-3361, https://doi.org/10.1002/joc.4213.

Du, M.-X., Z.-D. Lin, and R.-Y. Lu, 2017: Combined impact of inphase and out-of-phase variation between the northern East Asian low and western North Pacific subtropical high on East Asian summer rainfall. Atmos. Oceanic Sci. Lett., 10, 284-290, https://doi.org/10.1080/16742834.2017.1312262.

Du, Y., L. Yang, and S.-P. Xie, 2011: Tropical Indian Ocean influence on northwest Pacific tropical cyclones in summer following strong El Niño. J. Climate, 24, 315-322, https://doi.org/ 10.1175/2010JCLI3890.1.

Emanuel, K., 2010: Tropical cyclone activity downscaled from NOAA-CIRES reanalysis, 1908-1958. J. Adv. Model. Earth Syst., 2, 1-12, https://doi.org/10.3894/JAMES.2010.2.1.

—- and D. S. Nolan, 2004: Tropical cyclone activity and the global climate system. 26th Conf. on Hurricanes and Tropical Meteorology, Miami, FL, Amer. Meteor. Soc., 240-241.

Fan, L., S. I. Shin, Q. Liu, and Z. Liu, 2013: Relative importance of tropical SST anomalies in forcing East Asian summer monsoon circulation. Geophys. Res. Lett., 40, 2471-2477, https:// doi.org/10.1002/grl.50494.

Fan, Y., and K. Fan, 2017: Pacific decadal oscillation and the decadal change in the intensity of the interannual variability of the South China Sea summer monsoon. Atmos. Oceanic Sci. Lett., 10, 162 167, https://doi.org/10.1080/16742834.2016.1256189.

Gao, H., S. Yang, A. Kumar, Z. Hu, B. Huang, Y. Li, and B. Jha, 2011: Variations of the East Asian mei-yu and simulation and prediction by the NCEP Climate Forecast System. J. Climate, 24, 94-108, https://doi.org/10.1175/2010JCLI3540.1.

Gao, Y., 2017: Shift of the principal mode of pan-Asian monsoon summer precipitation in terms of spatial pattern. Atmos. Oceanic Sci. Lett., 10, 221-227, https://doi.org/10.1080/16742834. 2017.1294460.

— and H. J. Wang, 2012: Pan-Asian monsoon and its definition, principal modes of precipitation, and variability features. $S c i$ China Earth Sci., 55, 787-795, https://doi.org/10.1007/s11430012-4382-7.

,-- , and D. B. Jiang, 2015a: An intercomparison of CMIP5 and CMIP3 models for interannual variability of summer precipitation in pan-Asian monsoon region. Int. J. Climatol., 35, 3770-3780, https://doi.org/10.1002/joc.4245.

,-- , and D. Chen, 2015b: The capability of ENSEMBLES models in predicting the principal modes of pan-Asian monsoon precipitation. J. Climate, 28, 8486-8510, https://doi.org/ 10.1175/JCLI-D-15-0010.1.

,$- \ldots$, and,- 2018 : Precipitation anomalies in the panAsian monsoon region during El Niño decaying summer 2016. Int. J. Climatol., 38, 3618-3632, https://doi.org/10.1002/ joc.5522.

Harr, P. A., and R. L. Elsberry, 1995: Large-scale circulation variability over the tropical western North Pacific. Part I: Spatial patterns and tropical cyclone characteristics. Mon Wea. Rev., 123, 1225-1246, https://doi.org/10.1175/15200493(1995) $123<1225:$ LSCVOT $>2.0$. CO;2.

He, M., W. L. Song, and X. F. Chen, 1999: Typhoon activity in the northwest Pacific in relation to El Niño/La Niña events (in Chinese). J. Trop. Meteor., 15, 17-25.
He, S., Y. Gao, T. Furevik, H. Wang, and F. Li, 2018: Teleconnection between sea ice in the Barents Sea in June and the Silk Road, Pacific-Japan and East Asian rainfall patterns in August. Adv. Atmos. Sci., 35, 52-64, https://doi.org/10.1007/ s00376-017-7029-y.

Hu, Z. Z., 1997: Interdecadal variability of summer climate over East Asia and its association with $500 \mathrm{hPa}$ height and global sea surface temperature. J. Geophys. Res., 102, 19 403-19412, https://doi.org/10.1029/97JD01052.

Huang, R., Y. Xu, P. Wang, and L. Zhou, 1998: The features of the catastrophic flood over the Changjiang River basin during the summer of 1998 and cause exploration. Climatic Environ. Res., 3, 300-313.

Huangfu, J., R. Huang, W. Chen, and T. Feng, 2018: Causes of the active typhoon season in 2016 following a strong El Niño with a comparison to 1998. Int. J. Climatol., 38, e1107-e1118, https://doi.org/10.1002/joc.5437.

Ju, J., and J. Slingo, 1995: The Asian summer monsoon and ENSO. Quart. J. Roy. Meteor. Soc., 121, 1133-1168, https://doi.org/ 10.1002/qj.49712152509.

Kalnay, E., and Coauthors, 1996: The NCEP/NCAR 40-Year Reanalysis Project. Bull. Amer. Meteor. Soc., 77, 437-472, https:// doi.org/10.1175/1520-0477(1996)077<0437:TNYRP>2.0.CO;2.

Knapp, K. R., M. C. Kruk, D. H. Levinson, H. J. Diamond, and C. J. Neumann, 2010: The International Best Track Archive for Climate Stewardship (IBTrACS): Unifying tropical cyclone data. Bull. Amer. Meteor. Soc., 91, 363-376, https://doi.org/ 10.1175/2009BAMS2755.1.

Kruk, M. C., K. R. Knapp, and D. H. Levinson, 2010: A technique for combining global tropical cyclone best track data. J. Atmos. Oceanic Technol., 27, 680-692, https://doi.org/ 10.1175/2009JTECHA1267.1.

Lau, K.-M., and H. Weng, 2001: Coherent modes of global SST and summer rainfall over China: An assessment of the regional impacts of the 1997-98 El Niño. J. Climate, 14, 1294-1308, https://doi.org/10.1175/1520-0442(2001)014<1294: CMOGSA $>2.0 . \mathrm{CO} ; 2$.

Li, C. F., W. Chen, X. W. Hong, and R. Y. Lu, 2017: Why was the strengthening of rainfall in summer over the Yangtze River valley in 2016 less pronounced than that in 1998 under similar preceding El Niño events?-Role of midlatitude circulation in August. Adv. Atmos. Sci., 34, 1290-1300, https://doi.org/ 10.1007/s00376-017-7003-8.

Li, R. C. Y., and W. Zhou, 2012: Changes in western Pacific tropical cyclones associated with the El Niño-Southern Oscillation cycle. J. Climate, 25, 5864-5878, https://doi.org/10.1175/JCLID-11-00430.1.

— and _ 2013a: Modulation of western North Pacific tropical cyclone activities by the ISO. Part I: Genesis and intensity. J. Climate, 26, 2904-2918, https://doi.org/10.1175/JCLI-D-1200210.1.

, and _ 2013b: Modulation of western North Pacific tropical cyclone activities by the ISO. Part II: Tracks and landfalls. J. Climate, 26, 2919-2930, https://doi.org/10.1175/JCLI-D-1200211.1.

Li, T., B. Wang, B. Wu, T. J. Zhou, C.-P. Chang, and R. H. Zhang, 2017: Theories on formation of an anomalous anticyclone in western North Pacific during El Niño: A review. J. Meteor. Res., 31, 987-1006, https://doi.org/10.1007/ s13351-017-7147-6.

Lin, I.-I., and J. C. L. Chan, 2015: Recent decrease in typhoon destructive potential and global warming implications. Nat. Commun., 6, 7182, https://doi.org/10.1038/ncomms8182. 
Lin, Z. D., and R. Y. Lu, 2009: The ENSOs effect on eastern China rainfall in the following early summer. Adv. Atmos. Sci., 26, 333-342, https://doi.org/10.1007/s00376-009-0333-4.

Liu, J., B. Wang, and J. Yang, 2008: Forced and internal modes of variability of the East Asian summer monsoon. Climate Past, 4, 225-233, https://doi.org/10.5194/cp-4-225-2008.

Lu, R., and D. W. Dong, 2001: Westward extension of North Pacific subtropical high in summer. J. Meteor. Soc. Japan, 79, 12291241, https://doi.org/10.2151/jmsj.79.1229.

Ma, J., H. Wang, and K. Fan, 2015: Dynamic downscaling of summer precipitation prediction over China in 1998 using WRF and CCSM4. Adv. Atmos. Sci., 32, 577-584, https:// doi.org/10.1007/s00376-014-4143-y.

Otterå, O. H., 2008: Simulating the effects of the 1991 Mount Pinatubo volcanic eruption using the ARPEGE atmosphere general circulation model. Adv. Atmos. Sci., 25, 213-226, https://doi.org/10.1007/s00376-008-0213-3.

Paek, H., J.-Y. Yu, F. Zheng, and M.-M. Lu, 2019: Impacts of ENSO diversity on the western Pacific and North Pacific subtropical highs during boreal summer. Climate Dyn., 52, 7153-7172, https://doi.org/10.1007/s00382-016-3288-z.

Park, D.-S. R., C.-H. Ho, J.- H. Kim, and H.-S. Kim, 2013: Spatially inhomogeneous trends of tropical cyclone intensity over the western North Pacific for 1977-2010. J. Climate, 26, 5088-5101, https://doi.org/10.1175/JCLI-D12-00386.1.

Shen, S., and K.-M. Lau, 1995: Biennial oscillation associated with the East Asian summer monsoon and tropical sea surface temperatures. J. Meteor. Soc. Japan, 73, 105-124, https:// doi.org/10.2151/jmsj1965.73.1_105.

Smith, T. M., R. W. Reynolds, T. C. Peterson, and J. Lawrimore, 2008: Improvements to NOAA's historical merged landocean surface temperature analysis (1880-2006). J. Climate, 21, 2283-2296, https://doi.org/10.1175/2007JCLI2100.1.

Sui, C.-H., P.-H. Chung, and T. Li, 2007: Interannual and interdecadal variability of the summertime western North Pacific subtropical high. Geophys. Res. Lett., 34, L11701, https:// doi.org/10.1029/2006GL029204.

Tao, S., Q. Zhang, and S. Zhang, 1998: The great floods in the Changjiang River valley in 1998 (in Chinese). Climatic Environ. Res., 3, 290-299.

Trenberth, K. E., 2007: Warmer oceans, stronger hurricanes. Evidence is mounting that global warming enhances a cyclone's damaging winds and flooding rains. Sci. Amer., 297, 44-51, https://doi.org/10.1038/scientificamerican0707-44.

Wang, B., and J. C. L. Chan, 2002: How strong ENSO events affect tropical storm activity over the western North Pacific. J. Climate, 15, 1643-1658, https://doi.org/10.1175/1520-0442(2002)015<1643: HSEEAT $>2.0 . \mathrm{CO} ; 2$.

_- and T. Li, 2004: East Asian monsoon and ENSO interaction. East Asian Monsoon, C.-P. Chang, Ed., World Scientific Publishing, 172-212.

- R. Wu, and X. Fu, 2000: Pacific-East Asian teleconnection: How does ENSO affect East Asian climate? J. Climate, 13, 1517-1536, https://doi.org/10.1175/1520-0442(2000)013<1517: PEATHD $>2.0 . \mathrm{CO} ; 2$.

-—, Q. Ding, X. Fu, I.-S. Kang, K. Jin, J. Shukla, and F. Doblas-Reyes, 2005: Fundamental challenge in simulation and prediction of summer monsoon rainfall. Geophys. Res. Lett., 32, L15711, https://doi.org/10.1029/ 2005 GL022734.

— J. Jiu, J. Yang, T. Zhou, and Z. Wu, 2009: Distinct principal modes of early and late summer rainfall anomalies in East
Asia. J. Climate, 22, 3864-3875, https://doi.org/10.1175/ 2009JCLI2850.1.

Wang, H. J., K. Fan, X. M. Lang, J. Q. Sun, and L. J. Chen, 2012a: Advances in Climate Prediction Theory and Technique of China. China Meteorological Press, 226 pp.

— , and Coauthors, 2012b: Extreme climate in China: Facts, simulation and projection. Meteor. Z., 21, 279-304, https:// doi.org/10.1127/0941-2948/2012/0330.

Wu, B., T. J. Zhou, and T. Li, 2017a: Atmospheric dynamic and thermodynamic processes driving the western North Pacific anomalous anticyclone during El Niño. Part I: Maintenance mechanisms. J. Climate, 30, 9621-9635, https://doi.org/10.1175/ JCLI-D-16-0489.1.

,-- , and $-2017 \mathrm{~b}$ : Atmospheric dynamic and thermodynamic processes driving the western North Pacific anomalous anticyclone during El Niño. Part II: Formation processes. J. Climate, 30, 9637-9650, https://doi.org/10.1175/JCLI-D-160495.1.

Xie, P., and P. A. Arkin, 1997: Global precipitation: A 17-year monthly analysis based on gauge observations, satellite estimates, and numerical model outputs. Bull. Amer. Meteor. Soc., 78, 2539-2558, https://doi.org/10.1175/1520-0477(1997) 078<2539:GPAYMA $>2.0$.CO;2.

Xie, S.-P., J. Hafner, H. Tokinaga, Y. Du, G. Huang, and T. Sampe, 2009: Indian Ocean capacitor effect on Indo-western Pacific climate during the summer following El Niño. J. Climate, 22, 730-747, https://doi.org/10.1175/2008JCLI2544.1.

Xie, Z., Y. Du, and S. Yang, 2015: Zonal extension and retraction of the subtropical westerly jet stream and evolution of precipitation over East Asia and the western Pacific. J. Climate, 28, 6783-6798, https://doi.org/10.1175/JCLI-D14-00649.1.

Xue, F., and C.-Z. Liu, 2008: The influence of moderate ENSO on summer rainfall in eastern China and its comparison with strong ENSO. Chin. Sci. Bull., 53, 791-800, https://doi.org/ 10.1007/s11434-008-0002-5.

Xue, X., W. Chen, S. Chen, and D. W. Zhou, 2015: Modulation of the connection between boreal winter ENSO and the South Asian high in the following summer by the stratospheric quasibiennial oscillation. J. Geophys. Res., 120, 7393-7411, https:// doi.org/10.1002/2015JD023260.

Yan, Q., and Z. Zhang, 2017: Dominating roles of ice sheets and insolation in variation of tropical cyclone genesis potential over the North Atlantic during the last 21,000 years. Geophys. Res. Lett., 44, 10 624-10 632, https://doi.org/10.1002/ 2017 GL075786.

—, R. Korty, and Z. Zhang, 2015: Tropical cyclone genesis factors in a simulation of the last two millennia: Results from the Community Earth System Model. J. Climate, 28, 7182-7202, https://doi.org/10.1175/JCLI-D-15-0054.1.

- T. Wei, R. Korty, J. P. Kossin, Z. Zhang, and H. Wang, 2016: Enhanced intensity of global tropical cyclones during the midPliocene warm period. Proc. Natl. Acad. Sci. USA, 113, 12 963-12 967, https://doi.org/10.1073/pnas.1608950113.

Yang, S., and X. Jiang, 2014: Prediction of eastern and central Pacific ENSO events and their impacts on East Asian climate by the NCEP Climate Forecast System. J. Climate, 27, 44514472, https://doi.org/10.1175/JCLI-D-13-00471.1.

Zhang, R. H., Q. Y. Min, and J. Z. Su, 2017: Impact of El Niño on atmospheric circulations over East Asia and rainfall in China: Role of the anomalous western North Pacific anticyclone. Sci. China Earth Sci., 60, 1124-1132, https://doi.org/10.1007/s11430016-9026-x. 
Zhang, W., and Coauthors, 2016: Unraveling El Niño's impact on the East Asian monsoon and Yangtze River summer flooding. Geophys. Res. Lett., 43, 11 375-11 382, https://doi.org/10.1002/ 2016GL071190.

Zhou, B. T., 2011: Linkage between winter sea surface temperature east of Australia and summer precipitation in the Yangtze River valley and a possible physical mechanism. Sci. Bull., 56, 1821-1827, https://doi.org/10.1007/s11434-011-4497-9.
Zhou, T. J., and Coauthors, 2009: Why the western Pacific subtropical high has extended westward since the late 1970s. J. Climate, 22, 2199-2215, https://doi.org/10.1175/ 2008JCLI2527.1.

Zhu, Y., H. Wang, W. Zhou, and J. Ma, 2011: Recent changes in the summer precipitation pattern in East China and the background circulation. Climate Dyn., 36, 1463-1473, https:// doi.org/10.1007/s00382-010-0852-9. 